\title{
ON THE INTERSECTION GRAPHS ASSOCIETED TO POSETS
}

\author{
M. AfKhami ${ }^{1 *}$, K. Khashyarmanesh ${ }^{2}$ \\ AND \\ F. SHAHSAVAR ${ }^{2}$ \\ ${ }^{1}$ Department of Mathematics, University of Neyshabur \\ P.O. Box 91136-899, Neyshabur, Iran \\ ${ }^{2}$ Department of Pure Mathematics, Ferdowsi University of Mashhad \\ P.O. Box 1159-91775, Mashhad, Iran \\ e-mail: mojgan.afkhami@yahoo.com \\ khashyar@ipm.ir \\ fa.shahsavar@yahoo.com
}

\begin{abstract}
Let $(P, \leq)$ be a poset with the least element 0 . The intersection graph of ideals of $P$, denoted by $G(P)$, is a graph whose vertices are all nontrivial ideals of $P$ and two distinct vertices $I$ and $J$ are adjacent if and only if $I \cap J \neq\{0\}$. In this paper, we study the planarity and outerplanarity of the intersection graph $G(P)$. Also, we determine all posets with split intersection graphs.
\end{abstract}

Keywords: poset, intersection graph, split graph, planar graph, outerplanar graph.

2010 Mathematics Subject Classification: 05C10, 06A07.

\section{REFERENCES}

[1] M. Afkhami and K. Khashyarmanesh, The intersection graphs of ideals of posets, Discrete Math. Algorithms and Appl. 6 (2014) 1450036-1450045. doi:10.1142/S1793830914500360

[2] M. Afkhami and K. Khashyarmanesh, The cozero-divisor graph of a commutative ring, Southeast Asian Bull. Math. 35 (2011) 753-762.

\footnotetext{
${ }^{*}$ Corresponding author.
} 
[3] D.F. Anderson, M.C. Axtell and J.A. Stickles, Zero-divisor graphs in commutative rings, Commutative Algebra, Noetherian and Non-Noetherian Perspectives (M. Fontana, S.E. Kabbaj, B. Olberding, I. Swanson), (Springer-Verlag, New York, 2011) $23-45$.

[4] D.F. Anderson and P.S. Livingston, The zero-divisor graph of a commutative ring, J. Algebra 217 (1999) 434-447. doi:10.1006/jabr.1998.7840

[5] I. Beck, Coloring of commutative rings, J. Algebra 116 (1998) 208-226. doi:10.1016/0021-8693(88)90202-5

[6] J.A Bondy and U.S.R. Murty, Graph Theory with Applications (American Elsevier, New York, 1976).

[7] J. Bosák, The graphs of semigroups, in: Theory of Graphs and Its Applications Proc. Symposium Smolenice, June 1963 (Praha, 1964).

[8] I. Chakrabarty, S. Ghosh, T.K. Mukherjee and M.K. Sen, Intersection graphs of ideals of rings, Discrete Math. 309 (2009) 5381-5392. doi:10.1016/j.disc.2008.11.034

[9] B. Csákány and G. Pollák, The graph of subgroups of a finite group, Czechoslovak Math. J. 19 (1969) 241-247.

[10] B.A. Davey and H.A. Priestley, Introduction to Lattices and Order (Cambridge University Press, 2002).

[11] E. Estaji and K. Khashyarmanesh, The zero-divisor graph of a lattice, Results. Math. 61 (2012) 1-11. doi:10.1007/s00025-010-0067-8

[12] I. Gitler, E. Reyes and R.H. Villarreal, Ring graphs and complete intersection toric ideals, Discrete Math. 310 (2010) 430-441. doi:10.1016/j.disc.2009.03.020

[13] D. Lu and T. Wu, On endomorphism-regularity of zero-divisor graphs, Discrete Math. 308 (2008) 4811-4815. doi:10.1016/j.disc.2007.08.057

[14] B. Zelinka, Intersection graphs of lattices, Math. Slovaca 23 (1973) 216-222.

[15] B. Zelinka, Intersection graphs of semilattices, Math. Slovaca 25 (1975) 345-350.

[16] B. Zelinka, Intersection graphs of finite abelian groups, Czechoslovak Math. J. 25 (1975) 171-174.

Received 24 July 2019

Revised 3 December 2019

Accepted 7 February 2020 